\title{
Management of Thrombotic Complications in COVID-19: An Update
}

\author{
Adrija Hajra ${ }^{1}$ (1) Sheetal Vasundara Mathai ${ }^{1} \cdot$ Somedeb Ball ${ }^{2} \cdot$ Dhrubajyoti Bandyopadhyay $^{3} \cdot$ Maedeh Veyseh $^{1}$. \\ Sandipan Chakraborty ${ }^{4} \cdot$ Carl J. Lavie $^{5} \cdot$ Wilbert S. Aronow $^{6}$
}

Published online: 16 August 2020

(c) Springer Nature Switzerland AG 2020

\begin{abstract}
Coronavirus disease 2019 (COVID-19), caused by severe acute respiratory syndrome coronavirus 2 (SARS-CoV-2), is now a global pandemic. This virus primarily affects the respiratory tract and causes lung injury characterized by acute respiratory distress syndrome. Although the pathophysiology of COVID-19 is not yet clear, the most widely accepted mechanism is systemic inflammation. A clinically significant effect of the inflammation is coagulopathy. As a result of this effect, patients are found to have a high risk of venous thromboembolism. Studies have reported a high incidence of thrombotic complications in critically ill patients with COVID-19. In this review, we discuss the most updated evidence on the pathophysiology, diagnosis, and treatment of the coagulopathy of COVID-19. Prophylactic anticoagulation is recommended for all in-patients with COVID-19. Those with a higher risk of developing thromboembolic events or who have already developed venous thromboembolism should be treated with therapeutic anticoagulation. We also discuss post-discharge prophylaxis for highrisk patients and some newly proposed treatments for the hypercoagulability that could improve the outcomes of the affected patients.
\end{abstract}

\section{Introduction}

The unrelenting storm of coronavirus disease 2019 (COVID19) caused by severe acute respiratory syndrome coronavirus 2 (SARS-CoV-2) continues to overwhelm the health systems worldwide. The infection has already resulted in 2 million cases and a death toll of greater than 100,000 in the USA alone [1]. The exact pathophysiology and management of this global pandemic are evolving. COVID-19 is an acute complex systemic disorder that, in its most severe state,

Adrija Hajra

adrija847@gmail.com

Sheetal Vasundara Mathai

sheetalmathai@gmail.com

Somedeb Ball

drsomedeb@gmail.com

Dhrubajyoti Bandyopadhyay

drdhrubajyoti87@gmail.com

Maedeh Veyseh

veysehm@nychhc.org

Sandipan Chakraborty

schakraborty591@gmail.com

Carl J. Lavie

clavie@ ochsner.org

Wilbert S. Aronow

wsaronow@aol.com presents with interstitial pneumonia progressing to acute respiratory distress syndrome (ARDS), sepsis, and multi-organ failure [2,3]. Current evidence points to a hypercoagulable state, a sequela of hyper-inflammation, to be an important pathogenic mechanism contributing to increased mortality in COVID-19 [4-6]. This theory is backed by the reports of elevated inflammatory and coagulation markers; and a correlation between elevated interleukin (IL)- 6 and fibrinogen levels $[7,8]$. It remains unknown whether the hypercoagulable state could be a direct consequence of SARS

1 Jacobi Medical Center/Albert Einstein College of Medicine, 1400 Pelham Pkwy S, The Bronx, NY 10461, USA

2 Texas Tech University Health Sciences Center, Lubbock, TX, USA

3 Icahn School of Medicine at Mount Sinai/Mount Sinai St. Luke's West Hospital, Manhattan, NY, USA

4 Miami Valley Hospital, Dayton, OH, USA

5 John Ochsner Heart and Vascular Institute, Ochsner Clinical School, The University of Queensland School of Medicine, New Orleans, LA, USA

6 Westchester Medical Center, New York Medical College, Valhalla, NY, USA 


\section{Key Points}

The clinical course of patients with COVID-19 may be complicated by coagulopathy leading to venous thromboembolism.

Patients with COVID-19 who are admitted to a hospital should be given prophylactic anticoagulation

Clinical suspicion and risk stratification are important to determine which group of patients would be treated with therapeutic anticoagulation.

$\mathrm{CoV}-2$ infection. Uncontrolled activation of the coagulation cascade resulting from the myriad effects of proinflammatory cytokines can lead to consumptive coagulopathy. The coagulation derangement includes sepsis-induced coagulopathy (SIC) and disseminated intravascular coagulation (DIC) [4]. In COVID-19, the balance of this coagulopathy is tipped towards the thrombotic end, with very few reported cases of bleeding.

In this article, we discuss the most updated evidence of pathophysiology, diagnosis, and management of thromboembolic complications in COVID-19. This article mainly focuses on the management of the thrombotic complication of COVID-19 including diagnosis and treatment. We integrate all the updated information from the available guidelines and highlight the potential new therapies. We have also attempted to divide the management into an inpatient and outpatient setting and also mention the strategy for follow-up.

\section{Epidemiology of Thrombosis in Coronavirus Disease 2019 (COVID-19)}

The reported incidence of various thrombotic events in patients with COVID-19 had a range of 7.7-49\% [5, 9-14], which is significantly higher than the incidence in patients without COVID. The individual studies listing the incidence and types of thrombotic complications are summarized in Table 1 [5, 9-14]. Patients were predominantly male with diabetes mellitus, hypertension, and cardiovascular diseases being the common comorbidities. A history of prior venous thromboembolism (VTE) was noted in about 3-5\% of patients [9-11].

The most prominent manifestation of coagulopathy among patients with COVID-19 was VTE, particularly pulmonary embolism. Cases of pulmonary embolism were more likely to be associated with higher D-dimer levels, admission to critical care units, treatment with mechanical ventilation, and prior heparin therapy $[14,15]$. However, there were reports of infrequent events of arterial thrombosis, characterized by ischemic strokes or acute coronary syndrome [9, 14]. Intensivists also encountered frequent clotting of circuits in the continuous renal replacement therapy or extracorporeal membrane oxygenation machines in these critically ill patients [10]. The mortality rate in these patients with COVID-19 and thrombotic events varied across studies, from 8 to $26 \%[9,10]$. A recent study describing autopsy reports from 12 patients with COVID-19 showed that massive pulmonary embolism was the cause of death in four out of those 12 patients; the source of the embolism was in the deep veins of the lower extremity [16].

\section{Pathophysiological Mechanisms of COVID-Associated Coagulopathy}

The implicated pathogenic mechanisms include thromboinflammation propagated by angiotensin-converting enzyme- 2 receptor-mediated pulmonary and vascular endothelial injury. The effect of endothelial damage is compounded by activation of the contact pathway by effects of individual components of neutrophil extracellular traps and microorganism-derived polyphosphates that activate platelets, mast cells, and factor XII. Other contributing mechanisms involve systemic complement activation (generalized activation of both alternative and lectin-based pathways) and pathogen-associated molecular patterns $[4,6,17,18]$. This is accompanied by a hypofibrinolytic state in the alveolar space created by an elevation of plasminogen activator inhibitor 1 derived from the lung epithelium and endothelial cells. Endothelial cell activation, triggered by elevated proinflammatory cytokines (IL-1, IL-6) and hypoxia secondary to ARDS, play a significant role in COVID-19 coagulopathy by increasing the tissue factor expression and subsequent propagation of coagulation cascade [19, 20]. A SARS CoV-2 infection-induced cytokine storm activates the coagulation pathway. Proinflammatory cytokines such as IL- $1 \beta$ and IL-6 stimulate the expression of tissue factor on immune cells and initiate extrinsic coagulation cascade activation. In contrast, the fibrinolytic system is suppressed as mentioned above. Platelets are activated by various proinflammatory cytokines and the damaged endothelium. Endothelial damage induced by inflammation further accelerates the thrombotic reaction.

The mechanism of activation of coagulation is described as follows: [21-23]:

- Endothelial damage leading to activation of tissue factor and platelets.

- Activation of tissue factors can induce generation of thrombin and fibrin. 


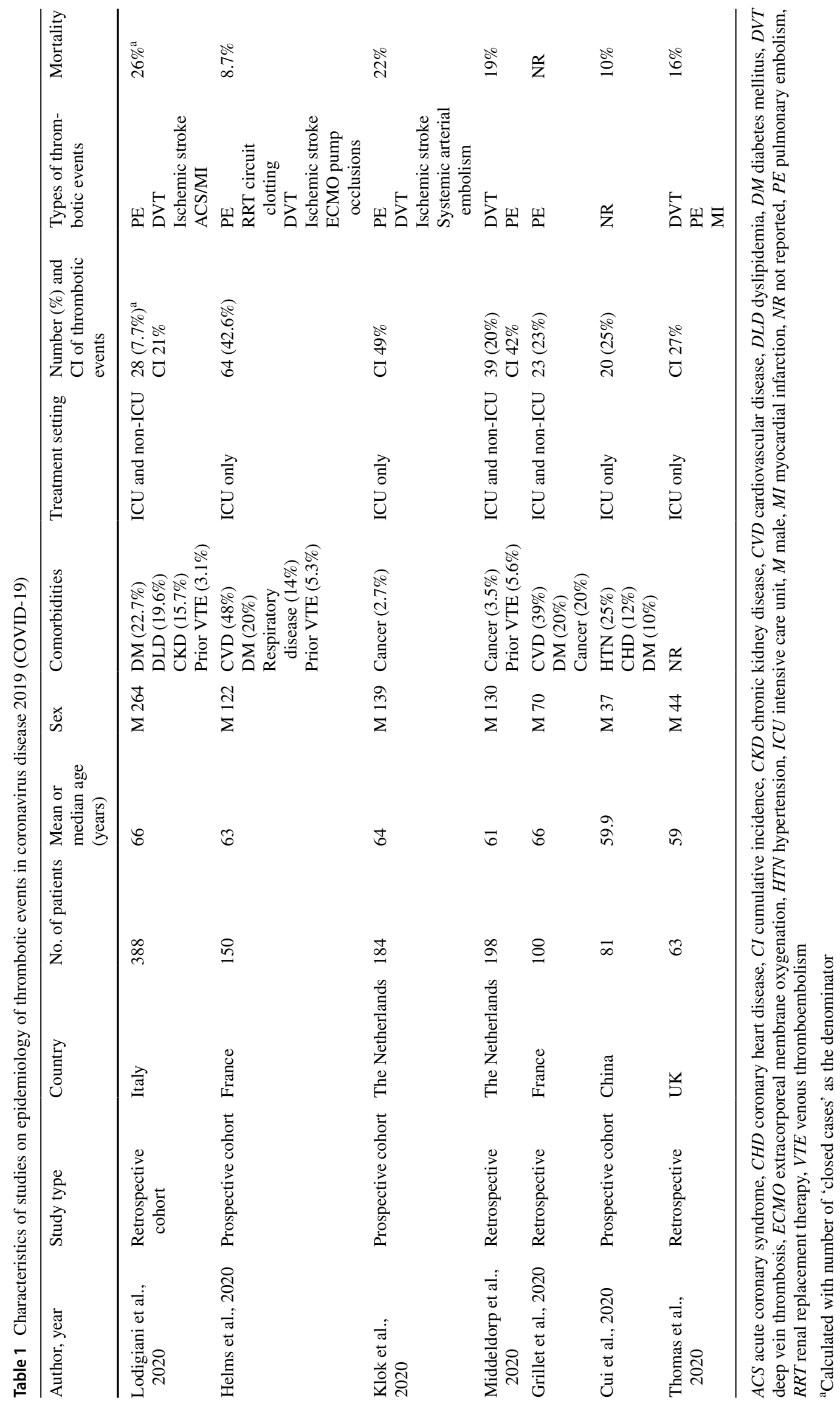


- Direct endothelial injury increases the risk of microangiopathy and microvascular clot formation.

- Proinflammatory cytokines can exaggerate microvascular injury and thrombus formation.

- Patients with acute respiratory distress syndrome resulting in hypoxia have an increased risk of hypoxia-induced endothelial damage.

- Activation of macrophages may also play role.

- Derangements in the renin angiotensin pathways may contribute to the hypercoagulable state of COVID-19.

Histologically, lung tissues from patients with COVID have showed florid capillary endotheliitis with formation of microthrombi in alveolar capillaries, and small pulmonary vessels [24]. Diffuse alveolar damage and inflammation, diffuse interstitial inflammation as well as extensive pulmonary macrophage activation play important roles in forming the microthrombi in the pulmonary vessels [22].

The net result of this alteration in the balance of coagulation and fibrinolytic pathways is fibrin deposition, as evidenced in patients with ARDS [6], as well as a multitude of other thrombotic complications. The occurrence of thrombosis in the pulmonary vasculature and other organ systems without evidence of embolic sources promotes local thrombosis as a probable hypothesis $[3,16]$. The reason for an increased D-dimer in patients with COVID-19 is not clear yet. Studies have shown that the increased D-dimer level was significantly correlated with inflammation, and this may also be the most reasonable explanation in patients with COVID19 [25].

The potential role of antiphospholipid antibodies in the pathogenesis of thrombotic events in patients with severe COVID-19 has recently been highlighted. However, articles have highlighted that in the setting of a high degree of inflammation and an increased level of inflammatory markers, those antibodies can be falsely positive. Recently, Macciò et al. have proposed an interesting pathogenesis thrombotic disorder in COVID-19. They discussed the role that reactive oxygen species can play in endothelial injury and activation of the coagulation cascade [26]. Factors such as critical illness, immobilization, multiple comorbidities, mechanical ventilation, and vascular access catheters exacerbate the pathophysiological mechanisms outlined above, resulting in the various thrombotic complications.

\section{Diagnosis of Venous Thromboembolism in COVID-19}

The diagnosis of VTE is primarily dependent on three modalities: clinical suspicion, laboratory data, and imaging. However, detection of VTE in patients with COVID-19 is challenging for various reasons, including the overlapping clinical symptoms of hypoxia and respiratory failure, technical difficulty of obtaining tests owing to the hemodynamic instability of critically ill patients on life-saving support systems and the infection precaution measures, and rapid clinical deterioration necessitating initiation of treatment even before confirmation of diagnosis. Patients with COVID-19 with severe disease are predisposed to develop renal, respiratory, and hepatic complications, which often preclude timely diagnosis and the management of thromboembolic and bleeding states [27]. Thus, prompt evaluation of these thromboembolic events is crucial in patients showing no clinical improvement and/or rapid clinical deterioration.

\section{Clinical Suspicion and Predictive Scoring Systems}

Clinical suspicion warranting a diagnosis of VTE is vital in patients exhibiting worsening tachypnea, decreased oxygen saturation $<90 \%$, increasing supplemental oxygen requirement, and hemodynamic instability in the setting of imaging findings inconsistent with worsening COVID-19 pneumonia [28]. Asymmetric limb pain or edema can raise clinical suspicion for deep vein thrombosis (DVT). Recognition of relevant symptoms and signs is vital, and if imaging/definitive diagnosis cannot be obtained, these patients should be started on appropriate anticoagulation therapy [29].

The risk of development of VTE can be assessed using several scoring systems, which can help to guide therapy. Studies suggest the use of Padua prediction score (factors such as previous VTE, active cancer, reduced mobility, known thrombophilic condition, recent trauma or surgery, age $\geq 70$ years, respiratory/cardiac failure, acute myocardial infarction/stroke, acute infection, obesity, and ongoing hormonal treatment are included; $<4$ : low risk of VTE; $\geq 4$ : high risk of VTE) or The International Medical Prevention Registry on Venous Thromboembolism (IMPROVE) score (which includes seven risk factors of active cancer, previous VTE, thrombophilia, lower limb paralysis, immobilization $<7$ days, intensive care unit/coronary care unit stay, age $>60$ years; more than one positive factor increases the risk of symptomatic VTE to 7.2\%) [30]. A recent study from China, using the Padua model, reported that $40 \%$ of hospitalized patients with COVID-19 were at high risk of developing VTE [31]. Obi et al. recommended using the Wells' score to determine the pre-test probability of DVT [32, 33] (Fig. 1).

\section{Laboratory Parameters}

Table 2 summarizes important findings from studies on laboratory markers and coagulation parameters used in the diagnosis of COVID-19. The derangement in levels of 
coagulation markers reflects the activation of the coagulation cascade. These findings have shown to be an indirect indicator of disease severity, heightened risk of thrombosis, and mortality [8, 10, 11, 13, 34]. Raised von Willebrand factor levels could be a surrogate marker of endotheliopathy $[10,35]$. A prospective study comparing coagulation parameter derangement among patients with COVID-19 and healthy controls found that the values of D-dimer (10.36 vs $0.26 \mathrm{ng} / \mathrm{L} ; p<0.001)$, fibrin/fibrinogen degradation products $(33.83 \mathrm{vs} 1.55 \mathrm{mg} / \mathrm{L} ; p<0.001)$, and fibrinogen $(5.02 \mathrm{vs}$ $2.90 \mathrm{~g} / \mathrm{L} ; p<0.001)$ in all SARS-CoV-2 cases were substantially higher than those in healthy controls. Moreover, D-dimer and fibrinogen degradation product values in patients with severe SARS-CoV-2 infection were higher than those in patients with mild disease [35]. A meta-analysis showed that patients with severe disease were found to have a significantly lower platelet count (mean difference: $-31 \times 10^{9} / \mathrm{L}, 95 \%$ confidence interval -35 to $-29 \times 10^{9} / \mathrm{L}$ ) and thrombocytopenia was associated with a five-fold higher odds of having the severe disease (odds ratio: $5.13 ; 95 \%$ confidence interval 1.81-14.58) [36]. An Italian study was conducted to determine the role of a thromboelastography point-of-care device in intensive care unit patients. These findings corresponded with elevated D-dimers, fibrinogen, C-reactive protein, factor VIII, and von Willebrand factor, highlighting the importance of anticoagulation [37].

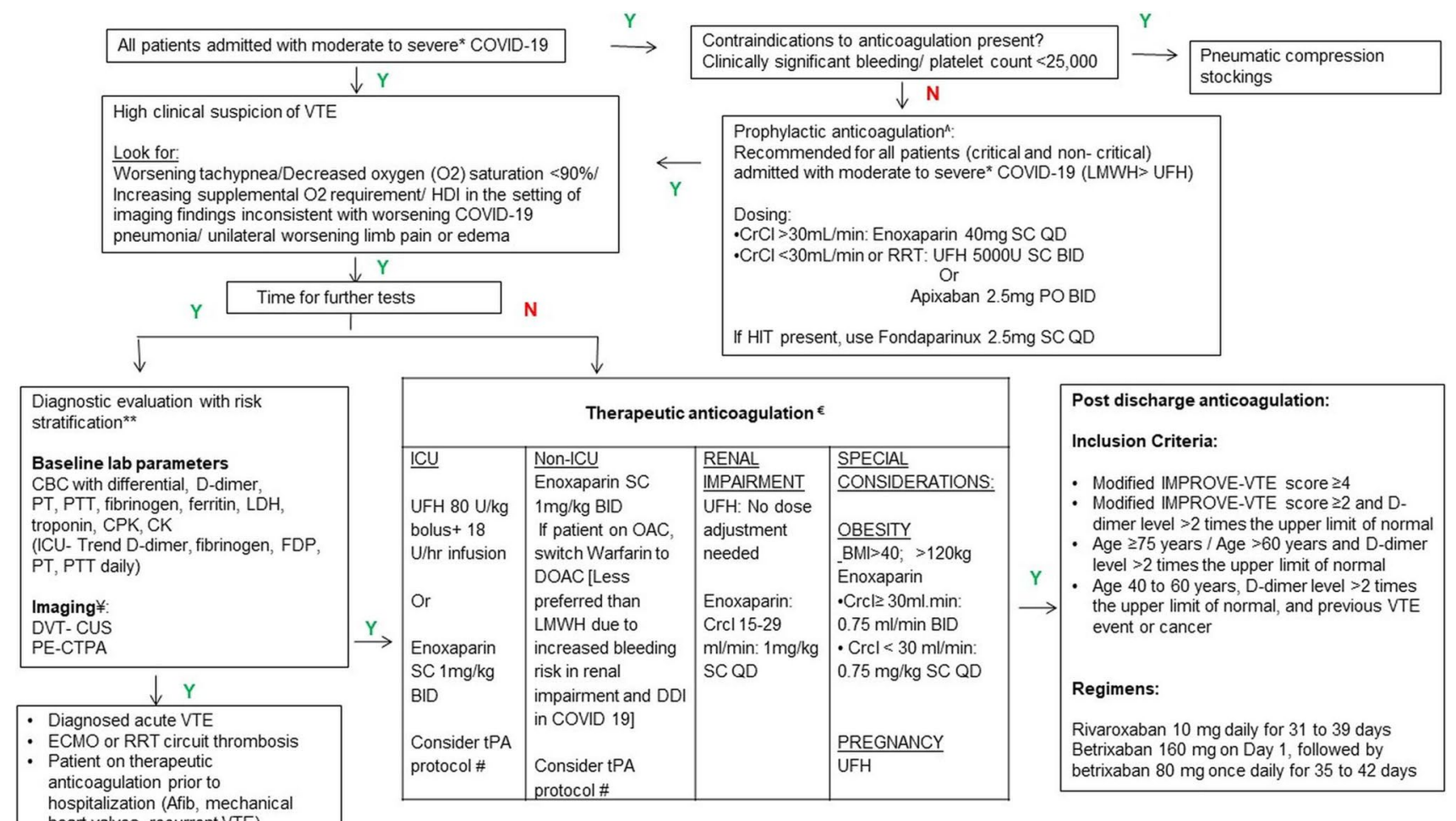

Fig. 1 Management of coronavirus disease 2019 (COVID-19)-associated coagulopathy $[22,23,27]$. Afib atrial fibrillation, $A R D S$ acute respiratory distress syndrome, $B I D$ twice a day, $B M I$ body mass index, $C B C$ complete blood count, $C K$ creatinine kinase, $C P K$ creatinine phosphokinase, $\mathrm{Crcl}$ creatinine clearance, CTPA computed tomography pulmonary angiography, $C U S$ compression ultrasonography, $D D I$ drug-drug interaction, $D O A C$ direct oral anticoagulant, $D V T$ deep vein thrombosis, ECMO extracorporeal membrane oxygenation, $H D I$ hemodynamic instability, HIT heparin induced thrombocytopenia, ICU intensive care unit, IMPROVE International Medical Prevention Registry on Venous Thromboembolism, $L D H$ lactate dehydrogenase, $L M W H$ low-molecular-weight heparin, $\mathrm{N}$ no, $\mathrm{O}_{2}$ oxygen, $O A C$ oral anticoagulation, $P E$ pulmonary embolism, $P T$ prothrombin time, $P T T$ partial thromboplastin time, $Q D$ once a day, $R R T$ renal replacement therapy, $S C$ subcutaneous, $t P A$ tissue plasminogen activator, $U F H$ unfractionated heparin, VTE venous thromboembolism, $Y$ yes. *Moderate COVID-19: evidence of lower respiratory illness by clinical assessment or imaging, with $\mathrm{SpO}_{2}>93 \%$ on room air at sea level. Severe COVID 19: $\mathrm{SpO}_{2} \leq 93 \%$ on room air at sea level, respiratory rate $>30, \mathrm{PaO}_{2} / \mathrm{FiO}_{2}<300$, or lung infiltrates $>50 \%$. Associated with ARDS, sepsis, and septic shock. Can progress to critical illness with cardiac, hepatic, renal, and central nervous system disease. **Risk stratification: VTE: PADUA/IMPROVE/Wells' scoring systems. DIC: ISTH scoring system. ${ }^{\wedge}$ If patient taking a DOAC or warfarin as an outpatient for routine indications (Afib, mechanical heart valves, recurrent VTE), switch to a therapeutic dose of LMWH (preferred to UFH as no PTT monitoring required) to decrease DDI. If patient is placed on UFH, monitor anti-Xa levels instead of PTT as latter shown to increase in severely ill patients with COVID-19 and confound results. ${ }^{¥}$ If CUS/CTPA is not feasible, consider bedside point-of-care ultrasonography or bedside cardiac ultrasound for unexplained acute right ventricular strain or intra-cardiac thrombus. ${ }^{\epsilon}$ Hematology consultation when required. ${ }^{\#}$ Cardiopulmonary deterioration due to $\mathrm{PE}$ 
Table 2 Variation in coagulation laboratory parameters in patients with coronavirus disease 2019 (COVID-19)

\begin{tabular}{|c|c|c|c|c|c|c|c|c|c|}
\hline Author, year & $\begin{array}{l}\text { Number } \\
\text { of patients }\end{array}$ & $\begin{array}{l}\text { Platelet count } \\
\left(10^{9} / \mathrm{L}\right)\end{array}$ & PT/INR & APTT & $\begin{array}{l}\text { Fibrino- } \\
\text { gen level }\end{array}$ & $\begin{array}{l}\text { D-dimer } \\
\text { level }\end{array}$ & Others & $\begin{array}{l}\text { Number of } \\
\text { patients with } \\
\text { positive DIC } \\
\text { score }\end{array}$ & Important findings \\
\hline $\begin{array}{l}\text { Helms et al., } \\
2020\end{array}$ & 150 & 200 & $\begin{array}{l}\text { PT } 84 \% \\
\text { INR } 1.12\end{array}$ & 1.2 & $6.99 \mathrm{~g} / \mathrm{L}$ & $2.27 \mathrm{mg} / \mathrm{L}$ & $\begin{array}{l}\text { vWF activity } \\
328 \% \\
\text { Factor VIII } \\
341 \% \\
\text { LA }+(n=50)\end{array}$ & $\begin{array}{l}\text { JAAM DIC } 6 \\
\text { ISTH } 0\end{array}$ & $\begin{array}{l}\text { Significant difference in coagula- } \\
\text { tion parameters between } 2 \text { groups } \\
\text { (patients with ARDS with and } \\
\text { without COVID-19) }\end{array}$ \\
\hline $\begin{array}{l}\text { Fogarty et al., } \\
2020\end{array}$ & 83 & 212 & PT $12.8 \mathrm{~s}$ & $31.1 \mathrm{~s}$ & $4.9 \mathrm{~g} / \mathrm{L}$ & $881 \mathrm{ng} / \mathrm{mL}$ & NR & ISTH 0 & $\begin{array}{l}\text { D-dimer levels on admission were } \\
\text { significantly higher in the subgroup } \\
\text { eventually needing ICU admission; } \\
\text { levels remained significantly higher } \\
\text { in poor subgroup even after } 4 \text { days }\end{array}$ \\
\hline $\begin{array}{l}\text { Middeldorp } \\
\text { et al., } 2020\end{array}$ & 198 & 239 & NR & NR & NR & $1.1 \mathrm{mg} / \mathrm{L}$ & NR & NR & $\begin{array}{l}\text { D-dimer level was significantly higher } \\
(2.0 \mathrm{vs} 1.1 \mathrm{mg} / \mathrm{L}, p=0.006) \text { in } \\
\text { patients admitted to ICU vs floor } \\
\text { Higher level was risk factor for VTE } \\
\text { on univariable regression analysis }\end{array}$ \\
\hline $\begin{array}{c}\text { Tang et al., } \\
2020\end{array}$ & 183 & NR & $13.7 \mathrm{~s}$ & $41.6 \mathrm{~s}$ & $4.55 \mathrm{~g} / \mathrm{L}$ & $\begin{array}{c}0.66 \mu \mathrm{g} / \\
\mathrm{mL}\end{array}$ & NR & ISTH 16 & $\begin{array}{l}\text { Non-survivors had significantly } \\
\text { higher D-dimer, FDP, and longer } \\
\text { PT and APTT on admission } \\
71.4 \% \text { of non-survivors met the crite- } \\
\text { ria of DIC during hospital stay }\end{array}$ \\
\hline $\begin{array}{l}\text { Cui et al., } \\
2020\end{array}$ & 81 & $246.6^{\mathrm{a}}$ & $15.4 \mathrm{~s}^{\mathrm{a}}$ & $39.9 \mathrm{~s}^{\mathrm{a}}$ & NR & $5.2 \mu \mathrm{g} / \mathrm{mL}^{\mathrm{a}}$ & NR & NR & $\begin{array}{l}\text { A D-dimer cut-off value of } 1.5 \mu \mathrm{g} / \\
\text { mL had } 85 \% \text { sensitivity and } 88.5 \% \\
\text { specificity for predicting VTE }\end{array}$ \\
\hline
\end{tabular}

APTT activated partial thromboplastin time, $A R D S$ acute respiratory distress syndrome, $D I C$ disseminated intravascular coagulation, FDP fibrin degradation products, ICU intensive care unit, INR international normalized ratio, ISTH International Society on Thrombosis and Hemostasis, $J A A M$ Japanese Association for Acute Medicine, LA lupus anticoagulant, $N R$ not reported, PT prothrombin time, $s$ seconds, VTE venous thromboembolism, $v W F$ Von Willebrand factor

${ }^{a}$ Value in the patients with VTE

Among those afflicted with COVID-19, the number of patients with an elevated International Society on Thrombosis and Hemostasis DIC score was low, while fibrinogen levels were elevated $[8,10,34]$. In one retrospective study including 183 patients with novel coronavirus pneumonia in China, non-survivors had significantly higher admission D-dimer and fibrinogen degradation product levels, and more prolonged prothrombin and partial thromboplastin times. In this study, $71.4 \%$ of non-survivors met the International Society on Thrombosis and Hemostasis criteria for overt DIC ( $>5$ points) [8]. Most of the studies have clinical data that support the fact that the coagulopathy in COVID-19 is thrombotic and occasionally manifests as acute DIC.

Studies from China have shown increased D-dimers $(0.5 \mathrm{mg} / \mathrm{L}$ or higher $)$ in $46-63 \%$ of patients with COVID19. Elevation in D-dimers was associated with higher rates of intensive care unit admission [11], development of ARDS, [10], and mortality [8]. One study found a D-dimer cut-off value of $1.5 \mu \mathrm{g} / \mathrm{mL}$ had $85 \%$ sensitivity and $88.5 \%$ specificity for VTE prediction in patients with COVID-19 [13]. However, the use of a D-dimer alone for risk stratification is not very useful for the following reasons: (1) elevated D-dimer levels are not specific for the diagnosis of VTE and (2) if only a high D-dimer level is relied on for diagnosis, it will unnecessarily increase the utilization of computed tomography pulmonary angiography (CTPA) without much benefit. Moreover, CTPA may worsen kidney function as a result of contrast use in critically ill patients [38].

\section{Imaging for Diagnosing Venous Thromboembolism}

Imaging studies can help yield a definitive diagnosis of VTE. Studies have shown the usefulness of compression ultrasonography and CTPA $[5,9,12]$. One study from Italy showed $16(36 \%)$ out of 44 patients had VTE on imaging, and ten (33\%) out of 30 patients had a pulmonary embolism on CTPA. More than $50 \%$ of VTE events were diagnosed within the first $24 \mathrm{~h}$ of hospital admission, highlighting the significance of early diagnosis and treatment in patients with COVID-19 [9]. The decision to perform an imaging study for diagnosing DVT should be based on clinical judgment. Routine screening for DVT in asymptomatic patients is not recommended [39]. 
However, the feasibility of these imaging modalities in the setting of COVID-19 is a matter of concern. Therefore, the role of bedside point-of-care ultrasound is important in aiding diagnosis. One recent multi-center study has shown $100 \%$ sensitivity and $95.8 \%$ specificity of point-of-care ultrasound for the diagnosis of DVT [40]. Bedside cardiac ultrasound also assists with the diagnosis of pulmonary embolism indirectly by instantaneous assessment of right ventricular size and function, especially in patients with high clinical suspicion. These bedside tests will enable rapid identification facilitating appropriate management of patients $[41,42]$. Ultrasound imaging will be particularly helpful in pregnant women, as it eliminates the risk of radiation [43].

\section{Treatment of Thrombotic Complication in COVID-19}

\subsection{Prophylactic Anticoagulation}

\subsubsection{In-Hospital}

The International Society on Thrombosis and Hemostasis has recommended the use of antithrombotic prophylaxis with low-molecular-weight heparin for all admitted patients unless there is a contraindication. In the setting of heparininduced thrombocytopenia, fondaparinux is recommended [44-46]. Routine thromboprophylaxis is not recommended in ambulatory patients with acute medical illness or respiratory symptoms [9]. Interestingly, the use of heparin is not only helpful for the anticoagulant effect, but also for its anti-inflammatory effect in patients with COVID-19 [47].

Heparin also has some protective effects on the endothelium. Direct drug delivery into the lung tissue through nebulized heparin may be an interesting treatment option to explore for its effects on the endothelium [48]. In vivo models of coronavirus infection have demonstrated the anti-viral effect of unfractionated heparin [49]. The choice of heparin over low-molecular-weight heparin is clinically relevant in patients with underlying renal dysfunction. Critically ill patients with COVID-19 may also develop liver dysfunction resulting in worsening of coagulopathy. These patients are at increased risk of bleeding. For these reasons, the type and dose of AC should be individualized based on their clinical picture $[21,49]$. In patients with a body mass index $\geq 40 \mathrm{~kg} /$ $\mathrm{m}^{2}$, a higher dose of thromboprophylaxis has been shown to decrease the odds of symptomatic VTE by $50 \%$ [50]. This strategy may be useful when treating obese patients with COVID-19.

\subsubsection{Post-Discharge}

Patients admitted to the hospital for acute medical illness have an increased risk of VTE up to 90 days after discharge. A similar risk should be considered for patients with COVID-19. It may be reasonable to consider extended treatment to prevent thromboembolic events after discharge from the hospitals. A regulatory-approved regimen can be used (betrixaban $160 \mathrm{mg}$ on day 1, followed by $80 \mathrm{mg}$ once daily for 35-42 days, or rivaroxaban $10 \mathrm{mg}$ daily for 31-39 days). Increased bleeding risk should be considered depending on the patient's clinical condition and comorbidities [44].

\subsection{Therapeutic Anticoagulation}

The treatment with a full dose of AC may be beneficial for patients who are meeting the criteria of a SIC score or who have a markedly elevated D-dimer level (Fig. 1). In a retrospective study involving 449 patients with severe COVID19 , Tang et al. showed lower 28-day mortality in patients who had a SIC score $\geq 4$ and a D-dimer level of $>3.0 \mu \mathrm{g} /$ $\mathrm{mL}$, and were treated with heparin (prophylactic dose of both low-molecular-weight heparin and unfractionated heparin) compared with patients who were not $(40.0 \%$ vs $64.2 \%$, $p=0.029$ ) [51]. It has been recommended to start therapeutic AC in patients with COVID-19 who have experienced an incident thromboembolic event or have a high suspicion of thromboembolic disease. Patients with COVID-19 requiring extracorporeal membrane oxygenation or continuous renal replacement therapy or who have thrombosis of the catheters or extracorporeal filters should be given therapeutic $\mathrm{AC}$ according to the standard institutional protocols [52]. A recently published study has found evidence of heparin resistance in critically ill patients with COVID-19. Measurement of the anti-factor Xa level may be useful in these patients $[4,53]$.

\subsection{Tissue Plasminogen Activator}

Few preclinical and clinical reports have suggested that fibrinolytic therapy may be useful in improving survival in patients with acute lung injury and ARDS [54, 55]. A recently published case series reported the effect of tissue plasminogen activator on patients with COVID-19 experiencing ARDS and respiratory failure. All of the three patients showed an initial improvement in their partial pressure of oxygen-to-fraction of inspired oxygen ratio. However, the effect was transient. More evidence is required to evaluate the impact of tissue plasminogen activator on the survival of individuals with COVID-19 [55]. 


\subsection{Oral Anticoagulation}

Patients taking warfarin and those who can take oral medication should be transitioned to the same depending on the indication. If there is an option for switching to direct oral ACs (DOACs), it should be done, because during isolation for COVID-19, regular international normalized ratio monitoring would likely be difficult [44]. The DOACs can be used in patients with COVID-19 as per the usual indications. To date, the use of DOACs in patients with COVID-19 admitted to a hospital is not routinely recommended. Direct oral ACs have drug-drug interactions with anti-IL-6 (tocilizumab) and anti-viral (lopinavir, ritonavir, or darunavir) medications. Furthermore, in the setting of renal impairment, a common complication in critically ill patients with COVID-19, reduced excretion of DOACs can increase the bleeding risk [44, 56-58].

\subsection{Newer Agents}

Asakura and Ogawa have discussed nafamostat, a serine protease inhibitor, as a potential AC treatment for patients with COVID-19. As nafamostat has weak anticoagulation actions, the authors have suggested combining it with heparin may augment its positive effects [59]. Recently, evidence from three COVID-19 pneumonia cases has shown improvement in clinical status following the administration of nafamostat [60].

As the cytokine storm has an important role in thrombosis in patients with COVID-19, anti-IL drugs may prove their role as a treatment option for affected patients. Studies are required to see the effect of tocilizumab (anti IL-6) and canakinumab (anti IL-1) for the treatment of COVID-19. Anti-human immunoglobulin G and an anti-Janus kinase inhibitor may also be potential treatment options [61, 62].

Patients with COVID-19 have been noted to have an increased risk of thrombosis. Apart from VTE, there is evidence that can raise concern for thrombotic risk in other vascular territories, including thrombosis in the coronary circulation [63]. Recently, one case report has shown anterior ST elevated myocardial infarction in an asymptomatic patient with COVID-19. The patient was treated with intravenous thrombolysis, followed by coronary rescue angioplasty. The patient developed two episodes of acute stent thrombosis at 2 and $36 \mathrm{~h}$ following admission despite optimal medical therapy. Acute inflammation and endothelial dysfunction in COVID-19 have been proposed as a potential mechanism for hypercoagulability. Additionally, excessive platelet aggregability may play a role resulting in in-stent thrombosis. The importance of anti-platelet drugs in this scenario should be reconsidered [64]. One recent article has discussed an interesting point regarding the use of ticagrelor. The authors have highlighted the role of ticagrelor not only for its antiplatelet action but also for inhibition of platelet-neutrophil aggregates, NET release, and vascular leakage preventing SIC [65].

\section{Conclusions}

COVID-19 is an ongoing, international public health crisis. The thrombotic complications secondary to the viral infection are being reported to be important drivers of multisystem involvement in the COVID-19 disease spectrum. Endothelial injury and proinflammatory cytokines in the setting of COVID-19 infection trigger activation of a coagulation cascade, leading to thromboembolic events. Diagnosis of VTE may be challenging in patients with COVID19 , mainly owing to clinical overlapping of symptoms and difficulty obtaining tests. For this reason, a high degree of clinical suspicion plays an important role for early diagnosis. Judicial use of predictive scoring models and appropriate imaging modalities are important for diagnosing the VTE events. Therapeutic anticoagulation with heparin should be promptly started as and when indicated. Future studies should investigate the nuances of the pathophysiology of COVID-19 coagulopathy and help establish guidelines on the use of laboratory biomarkers and the utility of direct oral anticoagulants in the acute setting.

Authors' contribution AH had the idea of the manuscript, prepared the outline, wrote the manuscript. SVM, SB wrote the manuscript, prepared the table and figure. DB, MV edited the manuscript, checked thereference. SC edited the manuscript, supervised. CJL supervised the manuscript. WSA supervised the manuscript.

\section{Declarations}

Funding No funding was received for the preparation of this article.

Conflict of interest Adrija Hajra, Sheetal Vasundara Mathai, Somedeb Ball, Dhrubajyoti Bandyopadhyay, Maedeh Veyseh, Sandipan Chakraborty, Carl J. Lavie, and Wilbert S. Aronow have no conflicts of interest that are directly relevant to the content of this article.

Ethics Approval Not applicable.

Consent to Participate Not applicable.

Consent for Publication Not applicable.

Availability of Data and Material Not applicable.

Code Availability Not applicable.

\section{References}

1. Center for Disease Control (CDC). Cases in the US. Available from: https://www.cdc.gov/coronavirus/2019-ncov/cases-updat es/cases-in-us.html. Accessed 10 June 2020. 
2. Terpos E, Ntanasis-Stathopoulos I, Elalamy I, Kastritis E, Sergentanis TN, Politou M, et al. Hematological findings and complications of COVID-19. Am J Hematol. 2020;95(7):834-47. https:// doi.org/10.1002/ajh.25829.

3. Cattaneo M, Bertinato EM, Birocchi S, Brizio C, Malavolta D, Manzoni M, et al. Pulmonary embolism or pulmonary thrombosis in COVID-19? Is the recommendation to use high-dose heparin for thromboprophylaxis justified? Thromb Haemost. 2020. https ://doi.org/10.1055/s-0040-1712097.

4. Connors JM, Levy JH. COVID-19 and its implications for thrombosis and anticoagulation. Blood. 2020;135(23):2033-40.

5. Klok FA, Kruip MJ, Van Der Meer NJ, Arbous MS, Gommers D, Kant KM, et al. Confirmation of the high cumulative incidence of thrombotic complications in critically ill ICU patients with COVID-19: an updated analysis. Thromb Res. 2020. https://doi. org/10.1016/j.thromres.2020.04.041

6. Whyte CS, Morrow GB, Mitchell JL, Chowdary P, Mutch NJ. Fibrinolytic abnormalities in acute respiratory distress syndrome (ARDS) and versatility of thrombolytic drugs to treat COVID-19. J Thromb Haemost. 2020. https://doi.org/10.1111/jth.14872.

7. Ranucci M, Ballotta A, Di Dedda U, Bayshnikova E, Dei Poli M, Resta M, et al. The procoagulant pattern of patients with COVID19 acute respiratory distress syndrome. J Thromb Haemost. 2020. https://doi.org/10.1111/jth.14854.

8. Tang N, Li D, Wang X, Sun Z. Abnormal coagulation parameters are associated with poor prognosis in patients with novel coronavirus pneumonia. J Thromb Haemost. 2020;18(4):844-7.

9. Lodigiani C, Iapichino G, Carenzo L, Cecconi M, Ferrazzi P, Sebastian T, et al. Venous and arterial thromboembolic complications in COVID-19 patients admitted to an academic hospital in Milan. Italy Thromb Res. 2020. https://doi.org/10.1016/j.throm res.2020.04.024.

10. Helms J, Tacquard C, Severac F, Leonard-Lorant I, Ohana M, Delabranche X, et al. High risk of thrombosis in patients with severe SARS-CoV-2 infection: a multicenter prospective cohort study. Intensive Care Med. 2020;46(6):1089-98. https://doi. org/10.1007/s00134-020-06062-X.

11. Middeldorp S, Coppens M, van Haaps TF, Foppen M, Vlaar AP, Müller MC, et al. Incidence of venous thromboembolism in hospitalized patients with COVID-19. J Thromb Haemost. 2020. https ://doi.org/10.1111/jth.14888.

12. Grillet F, Behr J, Calame P, Aubry S, Delabrousse E. Acute pulmonary embolism associated with COVID-19 pneumonia detected by pulmonary CT angiography. Radiology. 2020. https://doi. org/10.1148/radiol.2020201544.

13. Cui S, Chen S, Li X, Liu S, Wang F. Prevalence of venous thromboembolism in patients with severe novel coronavirus pneumonia. J Thromb Haemost. 2020. https://doi.org/10.1111/jth.14830.

14. Thomas W, Varley J, Johnston A, Symington E, Robinson M, Sheares K, et al. Thrombotic complications of patients admitted to intensive care with COVID-19 at a teaching hospital in the United Kingdom. Thromb Res. 2020;191:76-7.

15. Leonard-Lorant I, Delabranche X, Severac F, Helms J, Pauzet $\mathrm{C}$, Collange $\mathrm{O}$, et al. Acute pulmonary embolism in COVID-19 patients on CT angiography and relationship to D-dimer levels. Radiology. 2020. https://doi.org/10.1148/radiol.2020201561.

16. Wichmann D, Sperhake JP, Lütgehetmann M, Steurer S, Edler C, Heinemann A, et al. Autopsy findings and venous thromboembolism in patients with COVID-19: a prospective cohort study. Ann Internal Med. 2020. https://doi.org/10.7326/M20-2003.

17. Magro C, Mulvey JJ, Berlin D, Nuovo G, Salvatore S, Harp J, et al. Complement associated microvascular injury and thrombosis in the pathogenesis of severe COVID-19 infection: a report of five cases. Transl Res. 2020. https://doi.org/10.1016/j. trs1.2020.04.007.
18. Zuo Y, Yalavarthi S, Shi H, Gockman K, Zuo M, Madison JA, et al. Neutrophil extracellular traps in COVID-19. JCI Insight. 2020. https://doi.org/10.1172/jci.insight.138999.

19. Levi M, van der Poll T. Coagulation and sepsis. Thromb Res. 2017;149:38-44.

20. Ten VS, Pinsky DJ. Endothelial response to hypoxia: physiologic adaptation and pathologic dysfunction. Curr Opin Crit Care. 2002;8(3):242-50.

21. Iba T, Levy JH, Levi M, Connors JM, Thachil J. Coagulopathy of coronavirus disease 2019. Crit Care Med. 2020. https://doi. org/10.1097/CCM.0000000000004458.

22. McGonagle D, O'Donnell JS, Sharif K, Emery P, Bridgewood C. Immune mechanisms of pulmonary intravascular coagulopathy in COVID-19 pneumonia. Lancet Rheumatol. 2020. https://doi. org/10.1016/S2665-9913(20)30121-1.

23. Abou-Ismail MY, Diamond A, Kapoor S, Arafah Y, Nayak L. The hypercoagulable state in COVID-19: incidence, pathophysiology, and management. Thromb Res. 2020;194:101-15. https:// doi.org/10.1016/j.thromres.2020.06.029.

24. Bösmüller H, Traxler S, Bitzer M, Häberle H, Raiser W, Nann $\mathrm{D}$, et al. The evolution of pulmonary pathology in fatal COVID19 disease: an autopsy study with clinical correlation. Virchows Arch. 2020. https://doi.org/10.1007/s00428-020-02881-X.

25. Yu B, Li X, Chen J, Ouyang M, Zhang H, Zhao X, et al. Evaluation of variation in D-dimer levels among COVID-19 and bacterial pneumonia: a retrospective analysis. J Thromb Thrombolysis. 2020. https://doi.org/10.1007/s11239-020-02171-y.

26. Macciò A, Madeddu C, Caocci G, La Nasa G. Multifactorial pathogenesis of COVID-19-related coagulopathy: can defibrotide have a role in the early phases of coagulation disorders? J Thromb Haemost. 2020. https://doi.org/10.1111/jth.15021.

27. Wang T, Chen R, Liu C, Liang W, Guan W, Tang R, et al. Attention should be paid to venous thromboembolism prophylaxis in the management of COVID-19. Lancet Haematol. 2020;7(5):e362-e363363.

28. Available from: https://emergencymedicinecases.com/wp-conte nt/uploads/2020/04/COVID-19-Anticoagulation-Algorithm-versi on_final_1.1.pdf. Accessed 10 June 2020.

29. Available from: https://www.massgeneral.org/assets/MGH/pdf/ news/coronavirus/guidance-from-mass-general-hematology.pdf. Accessed 10 June 2020.

30. Bikdeli B, Madhavan MV, Jimenez D, Chuich T, Dreyfus I, Driggin E, et al. COVID-19 and thrombotic or thromboembolic disease: implications for prevention, antithrombotic therapy, and follow-up. J Am Coll Cardiol. 2020;75(23):2950-73.

31. Zhai Z, Li C, Chen Y, Gerotziafas G, Zhang Z, Wan J, et al. Prevention and treatment of venous thromboembolism associated with coronavirus disease 2019 infection: a consensus statement before guidelines. Thromb Haemost. 2020;120(06):937-48. https ://doi.org/10.1055/s-0040-1710019.

32. Obi AT, Barnes GD, Wakefield TW, Eliason JL, Arndt E, Henke PK. Practical diagnosis and treatment of suspected venous thromboembolism during COVID-19 pandemic. J Vasc Surg Venous Lymphat Disord. 2020;8(4):526-34. https://doi.org/10.1016/j. jvsv.2020.04.009.

33. NIH. Coronavirus disease 2019 (COVID-19) treatment guidelines. Available from: https://files.covid19treatmentguidelines.nih.gov/ guidelines/covid19treatmentguidelines.pdf. Accessed 12 June 2020.

34. Fogarty H, Townsend L, Ni Cheallaigh C, Bergin C, MartinLoeches I, Browne P, et al. COVID-19 coagulopathy in Caucasian patients. Br J Haematol. 2020. https://doi.org/10.1111/bjh.16749.

35. Han H, Yang L, Liu R, Liu F, Wu KL, Li J, et al. Prominent changes in blood coagulation of patients with SARS-CoV-2 infection. Clin Chem Lab Med. 2020. https://doi.org/10.1515/ cclm-2020-0188. 
36. Lippi G, Plebani M, Henry BM. Thrombocytopenia is associated with severe coronavirus disease 2019 (COVID-19) infections: a meta-analysis. Clin Chim Acta. 2020;506:145-8. https://doi. org/10.1016/j.cca.2020.03.022.

37. Panigada M, Bottino N, Tagliabue P, Grasselli G, Novembrino C, Chantarangkul V, et al. Hypercoagulability of COVID-19 patients in intensive care unit: a report of thromboelastography findings and other parameters of hemostasis. J Thromb Haemost. 2020. https://doi.org/10.1111/jth.14850.

38. Bandyopadhyay D, Akhtar T, Hajra A, Gupta M, Das A, Chakraborty S, et al. COVID-19 pandemic: cardiovascular complications and future implications. Am J Cardiovasc Drugs. 2020. https://doi.org/10.1007/s40256-020-00420-2.

39. Moores LK, Tritschler T, Brosnahan S, Carrier M, Collen JF, Doerschug K, et al. Prevention, diagnosis and treatment of venous thromboembolism in patients with COVID-19: CHEST Guideline and Expert Panel Report. Chest. 2020. https://doi.org/10.1016/j. chest.2020.05.559.

40. Fischer EA, Kinnear B, Sall D, Kelleher M, Sanchez O, Mathews B, et al. Hospitalist-operated compression ultrasonography: a point-of-care ultrasound study (HOCUS-POCUS). J Gen Intern Med. 2019;34(10):2062-7.

41. Tak T, Karturi S, Sharma U, Eckstein L, Poterucha JT, Sandoval Y. Acute pulmonary embolism: contemporary approach to diagnosis, risk-stratification, and management. Int J Angiol. 2019;28(2):100-11. https://doi.org/10.1055/s-0039-1692636.

42. Zhu R, Ma XC. Clinical value of ultrasonography in diagnosis of pulmonary embolism in critically ill patients. J Transl Intern Med. 2017;5(4):200-4.

43. Buonsenso D, Raffaelli F, Tamburrini E, Biasucci DG, Salvi $\mathrm{S}$, Smargiassi A, et al. Clinical role of lung ultrasound for the diagnosis and monitoring of COVID-19 pneumonia in pregnant women. Ultrasound Obstet Gynecol. 2020. https://doi. org/10.1002/uog.22055.

44. American Society of Hematology. COVID-19 and VTE/anticoagulation: frequently asked questions. Available from: https:// www.hematology.org/covid-19/covid-19-and-vte-anticoagulation . Accessed 13 June 2020.

45. Rotzinger DC, Beigelman-Aubry C, von Garnier C, Qanadli SD. Pulmonary embolism in patients with COVID-19: time to change the paradigm of computed tomography. Thromb Res. 2020;190:58-9. https://doi.org/10.1016/j.thromres.2020.04.011.

46. Thachil J, Tang N, Gando S, Falanga A, Cattaneo M, Levi M, et al. ISTH interim guidance on recognition and management of coagulopathy in COVID-19. J Thromb Haemost. 2020;18:1023-6. https://doi.org/10.1111/jth.14810.

47. Poterucha TJ, Libby P, Goldhaber SZ. More than an anticoagulant: do heparins have direct anti-inflammatory effects? Thromb Haemost. 2017;117(03):437-44.

48. Thachil J. The versatile heparin in COVID-19. J Thromb Haemost. 2020;18(5):1020-2. https://doi.org/10.1111/jth.14821.

49. Barrett CD, Moore HB, Yaffe MB, Moore EE. ISTH interim guidance on recognition and management of coagulopathy in COVID19: a comment. J Thromb Haemost. 2020. https://doi.org/10.1111/ jth. 14860 .

50. Wang TF, Milligan PE, Wong CA, Deal EN, Thoelke MS, Gage BF. Efficacy and safety of high dose thromboprophylaxis in morbidly obese inpatients. Thromb Haemost. 2014;111(1):88-93. https://doi.org/10.1160/TH13-01-0042.
51. Tang N, Bai H, Chen X, Gong J, Li D, Sun Z. Anticoagulant treatment is associated with decreased mortality in severe coronavirus disease 2019 patients with coagulopathy. J Thromb Haemost. 2020;18(5):1094-9. https://doi.org/10.1111/jth.14817.

52. NIH. Antithrombotic therapy in patients with COVID-19. Last updated: May 12, 2020. Available from: https://www.covid19tre atmentguidelines.nih.gov/antithrombotic-therapy/. Accessed 8 June 2020.

53. White D, MacDonald S, Bull T, Hayman M, de Monteverde-Robb $\mathrm{R}$, Sapsford D, et al. Heparin resistance in COVID-19 patients in the intensive care unit. J Thromb Thrombolysis. 2020. https://doi. org/10.1007/s11239-020-02145-0.

54. Hardaway RM, Williams CH, Marvasti M, et al. Prevention of adult respiratory distress syndrome with plasminogen activator in pigs. Crit Care Med. 1990;18:1413-8.

55. Wang J, Hajizadeh N, Moore EE, et al. Tissue plasminogen activator (tPA) treatment for COVID-19 associated acute respiratory distress syndrome (ARDS): a case series. J Thromb Haemost. 2020. https://doi.org/10.1111/jth.14828.

56. Thachil J, Tang N, Gando S, et al. DOACs and "newer" haemophilia therapies in COVID-19. J Thromb Haemost. 2020. https:// doi.org/10.1111/jth.14841.

57. Testa S, Paoletti O, Giorgi-Pierfranceschi M, Pan A. Switch from oral anticoagulants to parenteral heparin in SARS-CoV-2 hospitalized patients. Intern Emerg Med. 2020. https://doi.org/10.1007/ s11739-020-02331-1.

58. Testa S, Prandoni P, Paoletti O, Morandini R, Tala M, Dellanoce $\mathrm{C}$, et al. Direct oral anticoagulant plasma levels' striking increase in severe COVID-19 respiratory syndrome patients treated with antiviral agents: the Cremona experience. J Thromb Haemost. 2020;18:1320-3. https://doi.org/10.1111/jth.14871.

59. Asakura H, Ogawa H. Potential of heparin and nafamostat combination therapy for COVID-19. J Thromb Haemost. 2020;18(6):1521-2. https://doi.org/10.1111/jth.14858.

60. Jang S, Rhee JY. Three cases of treatment with nafamostat in elderly patients with COVID-19 pneumonia who need oxygen therapy. Int J Infect Dis. 2020. https://doi.org/10.1016/j. ijid.2020.05.072.

61. Magro G. COVID-19: review on latest available drugs and therapies against SARS-CoV-2. Coagulation and inflammation crosstalking. Virus Res. 2020;286:198070. https://doi.org/10.1016/j. virusres.2020.198070.

62. Ucciferri C, Auricchio A, Di Nicola M, Potere N, Abbate A, Cipollone $\mathrm{F}$, et al. Canakinumab in a subgroup of patients with COVID-19. Lancet Rheumatol. 2020. https://doi.org/10.1016/ S2665-9913(20)30167-3.

63. Dominguez-Erquicia P, Dobarro D, Raposeiras-Roubín S, Bastos-Fernandez G, Iñiguez-Romo A. Multivessel coronary thrombosis in a patient with COVID-19 pneumonia. Eur Heart J. 2020;41(22):2132. https://doi.org/10.1093/eurheartj/ehaa393.

64. Lacour T, Semaan C, Genet T, Ivanes F. Insights for increased risk of failed fibrinolytic therapy and stent thrombosis associated with COVID-19 in ST-segment elevation myocardial infarction patients. Catheter Cardiovasc Interv. 2020. https://doi. org/10.1002/ccd.28948.

65. Omarjee L, Meilhac O, Perrot F, Janin A, Mahe G. Can ticagrelor be used to prevent sepsis-induced coagulopathy in COVID19? Clin Immunol. 2020;216:108468. https://doi.org/10.1016/j. clim.2020.108468. 